\title{
Image-Based, Organ-Level Plant Phenotyping for Wheat Improvement
}

\author{
Cody S. Bekkering, Jin Huang and Li Tian * (D) \\ Department of Plant Sciences, University of California, Davis, CA 95616, USA; \\ csbekkering@ucdavis.edu (C.S.B.); jihuan@ucdavis.edu (J.H.) \\ * Correspondence: ltian@ucdavis.edu; Tel.: +1-530-752-0940
}

Received: 26 July 2020; Accepted: 27 August 2020; Published: 30 August 2020

check for updates

\begin{abstract}
Wheat was one of the first grain crops domesticated by humans and remains among the major contributors to the global calorie and protein budget. The rapidly expanding world population demands further enhancement of yield and performance of wheat. Phenotypic information has historically been instrumental in wheat breeding for improved traits. In the last two decades, a steadily growing collection of tools and imaging software have given us the ability to quantify shoot, root, and seed traits with progressively increasing accuracy and throughput. This review discusses challenges and advancements in image analysis platforms for wheat phenotyping at the organ level. Perspectives on how these collective phenotypes can inform basic research on understanding wheat physiology and breeding for wheat improvement are also provided.
\end{abstract}

Keywords: wheat; phenotype; phenotyping; phene; phenomics; shoot; root; seed; grain; imaging

\section{Introduction}

The rapid growth in world population calls for increased food production to meet the growing demand for calories. To this end, yields of wheat, a major staple food crop, will need to rise by $50 \%$ by 2050 as projected by CIMMYT [1]. The gains in yield will be brought on by basic research that explores wheat physiology and genetics, intensive breeding efforts, and innovative agronomic practices. Observing and quantifying plant phenotypes (i.e., phenotyping) is critical and integral to each of these efforts [2]. A phenotype is comprised of a collection of smaller measurable traits known as phenes [3]. The observed phenes and phenotypes of wheat at least partially dictate its agronomic performance while being indicative of its underlying physiology and genetics as well as its interaction with the environment. In spite of its relevance, phenotypic information is acquired at a rate that has been outpaced by that of genetic information by virtue of recent breakthroughs in genomics, sequencing, and genetic marker development. This has led to what is dubbed the "phenotyping bottleneck": a constraint on the scale of plant breeding and research caused by current limitations to high-throughput and high-resolution phenotyping [2]. At the core of this phenotyping bottleneck is how phenotyping is conducted. Quantitatively phenotyping wheat plants commonly involves time-consuming, manual measurements that are constrained in their throughput. This is further complicated by the environmental effects on phenotypes, which necessitate replicated, multi-location trials and studies.

Many tools have been crafted to alleviate this phenotyping bottleneck. Such tools rely heavily on image analysis and often serve to either expedite manual measurements or to automate the measurements altogether [4]. For above-ground organs, the scale and the detail that one can assess phenotypic information have both expanded vastly due to the advancements of different classes of tools. For the expansion of scale, imaging from ground vehicles, drones, aircraft, and even satellites have proven immensely useful for quantitatively studying groups or populations of plants. Readers are directed to several excellent review articles on high-throughput phenotyping (phenomics) using sensor 
technologies [4-6]. The present review focuses on the imaging tools that have enabled greater resolution of phenotypes of individual wheat plants at the organ level. This is highly relevant to fundamental research that tackles questions pertinent to wheat physiology and stress response as well as field research that can provide invaluable data for wheat breeding. Special attention is given to cost-effective tools that do not possess a steep learning curve as to focus on tools that could be implemented in projects at a broad range of sizes. We aim to provide a point of reference for researchers that are new to phenotyping of wheat plants or are interested in exploring alternative phenotyping platforms. Use of these image-based tools has been and can be applied to other cereal grain crops or to crops in general.

\section{Phenotyping of Shoot Traits}

\subsection{Shoot Phenotyping in Wheat: An Overview}

Shoot traits such as leaf size, shoot height, spikelets per spike, tiller number, and maturity are amenable to non-destructive sampling and have been available to farmers, breeders, and researchers for centuries. However, quantification of shoot phenotypes of individual wheat plants is not limited to these "traditional" measures. Rather, shoot morphological analysis in wheat has been expanded to a greater collection of traits by virtue of image analysis software. At the simplest level, ImageJ [7] has enabled manual measurements of leaf shape, color, and extent of disease development $[8,9]$. Beyond the capabilities and throughput of ImageJ, additional tools have emerged that quantify familiar phenotypes from images with higher throughput or that compute relevant, novel phenotypes otherwise unavailable to researchers. Phenotypes assayed by these software tools vary greatly in their scope-with some tools analyzing leaves specifically and others zooming out to analyze individual shoots or to canopies formed by groups of plants (Table 1). While proprietary tools come at an added expense, publicly available tools enable researchers and breeders to quantitatively phenotype their plants while minimizing cost [10]. Such tools are often validated against their proprietary counterparts or against measurements in ImageJ to ensure phenotyping accuracy. Publicly available tools are often open source as well, with their source code being freely available for technically advanced users to tailor to their specific needs [10] (Table 1).

Table 1. Commonly used image-based tools for shoot phenotyping in wheat.

\begin{tabular}{|c|c|c|c|c|}
\hline Software & $\begin{array}{c}\text { Software/ } \\
\text { Hardware Cost }\end{array}$ & $\begin{array}{l}\text { Open } \\
\text { Source }\end{array}$ & Operating System & Example Output Trait \\
\hline Easy Leaf Area & No & Yes & Windows, Mac OS, Android & Total leaf area, leaf area index \\
\hline Lamina2Shape & No & Yes & N/A (MatLab Program) & $\begin{array}{c}\text { Leaf shape parameters, leaf length:width } \\
\text { ratio, leaf area }\end{array}$ \\
\hline LeafScan & Yes & No & iOS 9.2+ & Leaf area \\
\hline $\begin{array}{l}\text { Plant Screen } \\
\text { Mobile }\end{array}$ & No & Yes & Android OS 4+ & $\begin{array}{l}\text { Leaf area, perimeter, dimensions, } \\
\text { and color profiles }\end{array}$ \\
\hline LeafByte & No & Yes & iOS 9+ & Leaf area, herbivory extent \\
\hline Leaf Doctor & No & No & iOS $8+$ & Proportion of diseased leaf area \\
\hline BioLeaf & No & No & Android & Leaf area, herbivory extent \\
\hline HTPheno & No & Yes & N/A (ImageJ Plugin) & Shoot projected area, width, and height \\
\hline CoverageTool & No & Yes & Windows XP + & $\begin{array}{l}\text { Leaf area, color profiles, whole shoot } \\
\text { area/color, leaf area index }\end{array}$ \\
\hline Canopeo & No & No & $\begin{array}{l}\text { Windows 7+, Android, iOS, } \\
\text { Linux, Mac OS }\end{array}$ & Fractional green canopy cover \\
\hline CI-202 & Yes & No & Windows $95, \mathrm{XP}$ & $\begin{array}{l}\text { Leaf area, length, width, perimeter, } \\
\text { and aspect ratio }\end{array}$ \\
\hline LI-3000C & Yes & No & Windows $2000+$ & Leaf dimensions, leaf area \\
\hline WinDIAS & Yes & No & Windows 7+ & $\begin{array}{l}\text { Leaf area, length, width, perimeter, } \\
\text { proportion of diseased area }\end{array}$ \\
\hline WinFOLIA & Yes & No & Windows $8+$ & $\begin{array}{l}\text { Leaf area, leaf dimensions, herbivory } \\
\text { extent, disease extent, color profiles }\end{array}$ \\
\hline
\end{tabular}




\subsection{Phenotyping of Individual Leaves}

Multiple programs have been created that expedite quantification of leaf traits relative to manual quantification in Image (Table 1). At the most basic level, there are easily implemented options for assaying leaf area phenotypes. Easy Leaf Area [11] enables batch processing of camera or scanner images by quantifying the green area for each plant in each image while using a square red scale marker to calibrate its area measurements. The mobile app LeafScan [12], while coming at only a nominal cost to users, also simplifies leaf area measurements by calibrating area measurements to a square of fixed area in the image background. Another mobile app, Plant Screen Mobile [13], leverages a calibration object in smartphone images to rapidly measure leaf size and dimensions while also providing more options for color thresholding of leaves against more heterogeneous backgrounds. More complex leaf phenotypes, such as lamina shape (shape of leaf blade), can be assayed from scanned images using the MatLab program Lamina2Shape [14]. These leaf shape phenotypes are indicative of wheat's response to changes in agronomic practices such as sowing date, sowing density, and nitrogen fertilizer application, as leaf growth patterns are modulated to accommodate nutrient and space limitations $[15,16]$. Finally, the proprietary CI-202 Leaf Area Meter (CID Bio-Science, Camas, WA, USA) has a built-in scanner that flattens leaves and measures leaf perimeter, area, width, and length. This device is joined by other proprietary scanners that include the LI-3000C (LI-COR, Lincoln, NE, USA), and the WinDIAS system (Delta-T Devices, Cambridge, UK), which are advantaged for portability and throughout, respectively (Table 1).

Morphological traits such as shape are not the only relevant parameters in leaf phenotyping. Plants exist in environments where biotic stressors such as pests and diseases are present. Quantitatively assaying disease resistance and pest deterrence in leaves is important to research and breeding in wheat, as it provides valuable data for studies that elucidate key genes or linked molecular markers for biotic stress resistance. WinFOLIA (Regent Instruments, Quebec City, QC, Canada) is a proprietary software that quantifies herbivory and disease extent in addition to leaf morphological parameters. WinFOLIA has been implemented in research on monocot crops, such as studies of agronomic practices in maize [17] and disease response in barley [18]. In contrast to WinFOLIA, several leaf phenotyping freeware tools have the added benefit of being mobile applications, enabling enhanced portability relative to flatbed scanner systems. BioLeaf [19] and LeafByte [20] are freely available smartphone applications that can rapidly quantify the proportion of damage to leaves from pests. These apps considerably lower the equipment requirement for imaging leaf tissue and lower the technical learning curve for researchers and breeders that wish to approach pest damage and deterrence quantitatively. Another mobile application, Leaf Doctor [21], measures the proportion of diseased area on a leaf. This allows researchers to have quantitative measures of disease susceptibility rather than relying on coarse scales for disease grading [22]. This suite of leaf-level tools collectively gives research groups several options for leaf quantitative phenotyping based on the traits in consideration as well as the size and budget of the research project.

\subsection{Phenotyping of Individual Shoots}

Compared to individual leaves, phenotyping of whole shoots is technologically challenged by the inability for common imaging devices to capture information on three-dimensional (3D) structures. As a result, many phenotypes commonly assayed on whole shoots rely on the measurement of 2D projections of shoots taken with monocular (single camera) imaging systems [23,24]. Some of the leaf phenotyping programs survey the green area in images, making them suited to measure projected areas of whole shoots as well. For example, Easy Leaf Area can be used to batch process images of shoots to generate projected area measurements from a collection of images [11]. Likewise, ImageJ is still suited for fully manual measurements of area, height, and diameter of the shoot in the image [23,25]. CoverageTool [25] and HTPheno [23] are more specialized tools for whole shoot phenotyping. CoverageTool allows users to partition shoot images into regions by color and quickly quantify the projected area occupied by each color [25]. This enables rapid measurements of not only projected area, but also of senescence 
or tip dieback. HTPheno can batch process multiple images quickly that are taken with the same specifications, enabling the user to rapidly measure shoot width, height, and projected area without the need for manual measurements [23]. The usage of CoverageTool, HTPheno, and other shoot phenotyping software (such as Canopy Reconstruction [26]) is naturally constrained by the user's ability to quickly image shoots with consistent lighting, scales, and camera angles. Conveyor-assisted imaging systems that can generate images suitable for analysis with high throughput phenotyping software are constructed by companies such as Phenospex (Heerlen, Netherlands), Lemnatech (Aachen, Germany), and Qubit Phenomics (Kingston, ON, Canada). Such systems have been implemented at various centers worldwide [27] and have been used in the validation of software tools including HTPheno.

\subsection{Phenotyping of Canopy Cover}

Wheat shoots invariably come into contact with each other in the field setting. Communities of individual plants form canopies in which the spatial distribution of leaves collectively determines the productivity of the entire plot [28]. A common metric used to quantitatively analyze these plant canopies is the fractional green canopy cover (FGCC): the proportion of a given two-dimensional, vertically viewed area that is taken up by green shoot tissue. As with shoot phenotyping, programs that quantify green area in images such as ImageJ, CoverageTool, Easy Leaf Area, and Canopy Cover Free (a mobile app version of Easy Leaf Area) are appropriate for assaying the proportion of a plot image that is occupied by a plant canopy-effectively measuring FGCC. The mobile application Canopeo [29] is specialized for FGCC measurements and has been leveraged more extensively in wheat research in comparison. The Canopeo app semi-automatically processes images of wheat canopies taken by users with a smartphone while allowing users to append additional metadata or notes to each image [29]. As FGCC is computed as a unitless proportion of green area to non-green area, scale markers are not needed for imaging, which increases throughput and lowers equipment need. This app is compatible with a wide range of computer operating systems and is continually maintained, ensuring its longevity as new tools emerge [30]. The relatively shorter canopies of wheat benefit from being more accessible throughout the plant's life cycle than those of taller monocot crops such as sugarcane or maize, making the use of cost-effective, handheld imagery feasible for time-series measurements of wheat in the field or greenhouse. Each of the freeware tools mentioned here are able to robustly quantify FGCC from images taken in these settings irrespective of the imaging device used.

\subsection{Phenotyping of Shoot Chemical Content}

Image-based shoot phenotyping in the visible wavelengths can be complemented by information acquired using infrared (IR) spectroscopy. This approach uses reflectance of wavelengths in the near infrared (NIR) or short-wave infrared (SWIR) spectrum $(700 \mathrm{~nm}-2500 \mathrm{~nm})$ relative to that of visible wavelengths to make inferences about the chemistry and overall health of the plant. The use of hyperspectral cameras capable of scanning large regions of the IR spectrum has given IR imagery its well-documented role in aerial remote sensing [31] but has also given it versatile uses in organ-level phenotyping. Commercially available hyperspectral cameras have enabled shoot chemical phenotyping through the analysis of false-color images. Many field-portable spectroradiometers circumvent the need for image analysis altogether by reporting spectral data for a targeted imaging field, though this is at the expense of measurement area. At the simplest level, some handheld devices feature a "point and shoot" measurement method that quickly and easily measures spectral reflectance at a target location, though the collection of traits measured is more limited. The broad spectral range and the high spectral resolution of many currently available tools have enabled the usage of numerical spectral vegetation indices (SVIs) that can have modelled relationships with plant chemical and physiological status [32]. A commonly reported SVI is the Normalized Difference Vegetation Index (NDVI), which is computed using measured reflectance of the red and NIR bands [33]. NDVI measures are indicative of vigor and phenology in wheat [34], and each of the aforementioned tools can readily compute NDVI measures at varying scales. As NDVI serves as a suitable proxy for plant health, it has been used in 
exploration of nematode resistance [35], the effects of no-till practices [36], and the genetics of heat and drought resistance [37] in wheat.

Other SVIs have been developed beyond the NDVI that are applicable to shoot chemical phenotyping in wheat. One such index is the Normalized Water Index (NWI), which leverages water absorption of certain NIR wavelengths to estimate shoot water content [38]. Beyond shoot water content, concentration of pigments, such as anthocyanins, can be measured in NIR imagery using the anthocyanin reflectance index. This has proven useful in the detection of stress symptoms in wheat, particularly in response to yellow rust [39]. Finally, the Pigment Specific Simple Ratio for Chlorophyll $a$ has proven to be an effective way to measure Chlorophyll $a$ in field-grown wheat [40]. Other indices are being developed and explored as well that correlate with shoot nitrogen uptake, leaf nitrogen content, and yield components in wheat [41]. Further work on modelling relationships between SVIs and mineral macronutrient (N, P, K, S) and micronutrient (such as $\mathrm{Zn}, \mathrm{Fe}$, and $\mathrm{B}$ ) concentrations is underway [42]. Currently available hyperspectral devices are capable of assaying spectral regions that enable users to carry out research and breeding in wheat using these SVIs and others. These proximal sensing tools have no barrier to their implementation outside of the hardware cost, making them amenable to incorporation into experimental designs or breeding regimes without the need to substantially overhaul the experimental design or breeding pipeline.

\subsection{Research Trajectories in Shoot Phenotyping}

Aside from profound advances in aerial and satellite imagery for remote sensing [43], affordable, smaller-scale image-based phenotyping of shoot traits is becoming increasingly user-friendly and higher throughput. Field phenotyping at the scale of individual plants or small groups of plants is benefited by field-portable or handheld imaging devices. Increased availability of software capable of analyzing images taken by these devices in the field enables the exploration of research questions without the introduction of controlled environment as a confounding factor. The rapid expansion of mobile applications in this space that can generate valuable phenotypic information stands to benefit both research and breeding efforts in wheat. Indeed, breeding efforts are benefited by the rapid growth of low-cost shoot phenotyping systems through the enablement of participatory breeding in which growers can provide quantitative inputs to breeders without changing their growing operations [44]. Continued development is occurring in this space as deep learning approaches continue to be implemented in the development of wheat phenotyping software [45]. For example, faster and easier acquisition of shoot traits that have been thus far excluded from image-based shoot phenotyping, such as spike number and tiller count, is steadily becoming possible using deep learning facilitated image analysis [46].

\section{Phenotyping of Root Architectural Traits}

\subsection{Barriers and Strategies for Root Phenotyping}

Plants allocate a large percentage of their photosynthate produced in shoots to sink tissues, such as roots [47]. Roots are the interface with the soil that plants use for anchorage, water and nutrient uptake, and microbial symbiosis [48]. Compared to shoot phenotyping, quantifying the phenotypes and constituent phenes of roots poses additional challenges. Retrieving roots from the soil for visualization is destructive to the plant and is also likely to perturb the phenotypes that are being measured [48]. In addition, the complexity of root systems presents another issue for automated phenotyping efforts. Root intersections, branching, and the presence of fine roots beyond the researcher's imaging capacity pose barriers to root phenotyping that are not present when phenotyping aboveground tissues [49].

Simple excavation remains a relevant method for phenotyping roots of plants growing in the field ("shovelomics" [50]). However, researchers should take great care to maintain the integrity of the root system during excavation and subsequent washing. Although washed roots extracted from soil cores can be suspended in water and imaged with high contrast, soil coring fails to capture the whole root 
system in all but the younger plants. As such, root crowns, rather than the whole root system, are phenotyped for mature plants in shovelomics [50]. Hydroponic systems provide an alternative liquid medium for plant growth and non-destructive imaging. However, plants grown hydroponically will invariably differ in their root morphology relative to soil-grown plants [51]. Physical tools have also been devised that ameliorate the visualization constraint for root phenotyping. Glass-sided boxes of soil called rhizotrons (or rhizoboxes) enable a relatively coarse visualization of the root system by allowing the roots touching the glass wall to be observed and imaged [52]. Roots in the field have been approached with "minirhizotrons", which are long, periscope-equipped glass tubes inserted into the soil of agronomic plots. Like rhizotrons, minirhizotrons enable imaging of roots growing along the glass tube wall. Minirhizotrons are valuable for their ability to image roots continuously and non-destructively in situ, though they have limited ability to image entire root systems [53]. In recent years, $\mathrm{X}$-ray computed tomography has seen improved image resolution and quality and has been applied to generating 3D images of roots in situ [54].

Following image acquisition, the task of quantification of root architectural traits remains. Manual quantification through tracing of root images, despite providing relatively accurate measurements, is laborious and limited to simple root systems. On the other hand, recent advances in computer vision have produced several software tools for root phenotyping that collectively accommodate a large collection of imaging methods, plant species, and phenotypes [10]. Many such tools are applicable to wheat phenotyping (Table 2) and have been employed to address a wide range of research questions as discussed below.

Table 2. Commonly used image-based tools for root phenotyping in wheat.

\begin{tabular}{|c|c|c|c|c|c|}
\hline Software & $\begin{array}{c}\text { Software/ } \\
\text { Hardware Cost }\end{array}$ & $\begin{array}{l}\text { Open } \\
\text { Source }\end{array}$ & Operating System & Automation & Example Output Trait \\
\hline RootNav & No & Yes & Windows XP+ & Semi-automated & $\begin{array}{l}\text { Primary and lateral } \\
\text { root count, lengths, } \\
\text { angles. Convex hull } \\
\text { area. Network shape. }\end{array}$ \\
\hline SmartRoot & No & Yes & $\begin{array}{c}\text { Platform } \\
\text { independent } \\
\text { (ImageJ plugin) }\end{array}$ & Semi-automated & $\begin{array}{l}\text { Primary and lateral } \\
\text { root length, lateral root } \\
\text { density, root diameter, } \\
\text { insertion angles. }\end{array}$ \\
\hline GiA Roots & No & No & $\begin{array}{l}\text { Windows } 7+\text {, Mac } \\
\text { OS, Linux }\end{array}$ & $\begin{array}{c}\text { Fully } \\
\text { automated }\end{array}$ & $\begin{array}{c}\text { Total root length, area, } \\
\text { and volume. Convex } \\
\text { hull area. } \\
\text { Network shape. }\end{array}$ \\
\hline DIRT & No & Yes & $\begin{array}{l}\text { Platform } \\
\text { independent (Web } \\
\text { interface) }\end{array}$ & $\begin{array}{c}\text { Fully } \\
\text { automated }\end{array}$ & $\begin{array}{l}\text { Soil tissue angle. Root } \\
\text { density and } \\
\text { distribution. Network } \\
\text { depth, width, shape. }\end{array}$ \\
\hline saRIA & No & No & $\begin{array}{l}\text { N/A (MatLab } \\
\text { Program) }\end{array}$ & Semi-automated & $\begin{array}{l}\text { Total root length, area, } \\
\text { and volume. Number } \\
\text { of branching points. } \\
\text { Network depth, width, } \\
\text { and width distribution. }\end{array}$ \\
\hline SegRoot & No & Yes & $\begin{array}{l}\text { Windows 7+, Mac } \\
\text { OS, Linux }\end{array}$ & $\begin{array}{c}\text { Fully } \\
\text { automated }\end{array}$ & Root length. \\
\hline WinRHIZO & Yes & No & Windows 7, 8, 10 & $\begin{array}{c}\text { Fully } \\
\text { automated }\end{array}$ & $\begin{array}{l}\text { Root length, area, } \\
\text { volume and diameter. } \\
\text { Number of tips. Root } \\
\text { color profile. }\end{array}$ \\
\hline
\end{tabular}




\subsection{Software Applicable to Root Phenotyping in Wheat}

The freeware ROOTEDGE [55] and the proprietary phenotyping platform WinRHIZO (Regent Instruments, Quebec City, Canada) were the early imaging tools that emerged alongside of ImageJ. ROOTEDGE, an early alternative to hand measurements of root systems, received some proof-of-concept work on wheat roots [56], but was written for early versions of MS-DOS and has since been overshadowed by more recently released tools that can better distinguish roots from image backgrounds and that are compatible with more operating systems and image specifications. WinRHIZO is a closed-source, hardware-associated tool that gained traction early on because of its ability to robustly image and quantify roots. The scanners associated with WinRHIZO are calibrated and illuminated in a manner that minimizes shadows, though generic flatbed scanner images can also be analyzed with the WinRHIZO software. Early applications of WinRHIZO in wheat enabled evaluation of many traits and processes, such as the modelling of root length density [57] and the investigation of crop rotation [58]. This proprietary platform has sustained maintenance, which is a limitation of many publicly available freeware tools [30]. As a result, continued applications of WinRHIZO have been seen widely in wheat research. For example, this platform has been applied in genetic mapping of root traits [59-61], exploration of nutrient response [62-64], gauging response to water limitation $[60,65,66]$, and evaluation of germplasm [67], among a plethora of other studies. However, the cost associated with the WinRHIZO image analysis system (scanner and software) may be considered prohibitory to new users in spite of its utility. To that end, several freely available tools have emerged that have overcome many of the limitations of ROOTEDGE while providing a workaround for the cost limitation of WinRHIZO [10] (Table 2).

Among the freely available root phenotyping tools, there are varying levels of automation for root trait quantification. Semi-automation has the advantage of enabling the user to improve phenotyping accuracy by manually correcting errors made in root identification, though this comes at the expense of throughput [10]. SmartRoot [68] and RootNav [69] are semi-automated tools that have been applied in wheat research. SmartRoot is an open source, operating system-independent plugin for ImageJ. Primary or lateral roots in whole root systems can be automatically identified by SmartRoot. The user has the option to review the automatic identification for each root segment to ensure an accurate measurement of the imaged root system [68]. SmartRoot has been used in wheat research to characterize germplasm [70,71], analyze plant-plant interactions [72], and study potential breeding targets for root architectural traits [73].

RootNav is another open source, semi-automated phenotyping tool that distinguishes primary and lateral roots [69]. RootNav users specify root tips and the source of the roots in the image. The program will generate a system of primary and lateral roots using this information and using the pixel intensities in the image. The user can proofread this root system after it has been generated to ensure robust identification of the root network. The user also has the ability to change thresholding parameters in different regions of the image to enable detection of roots in backgrounds with inconsistent lighting [69]. The ability to analyze lateral roots in complex root systems has given many uses for RootNav in wheat research, such as studies linking seedling traits to yield components [74] and nitrogen uptake [75], as well as to studies delving into the genetic components of root architecture [76-78]. RootNav is continually maintained, and a second version of the tool has been released as a command-line operated Python program that leverages deep learning to more effectively identify roots [79].

Fully automated programs differ from their semi-automated counterparts in that the specifications for image processing and analysis are set at the start of individual runs, and these specifications are applied to all images in the batch. This considerably increases throughput, as the user is not tasked with proofreading each image in the dataset. However, accuracy may be compromised if the specifications are not set carefully or if the images are of inconsistent quality [4]. The now discontinued GiA Roots [80] was a fully automated program that had been leveraged in wheat research. GiA Roots identified root pixels from the background of batches of images using thresholding parameters that were set by the user prior to the analysis. The roots identified in this scheme were measured for traits 
such as length, length distribution, surface area, and convex area [80]. GiA Roots has been adopted to study components of seedling water deficit response [81-83] and linkage drag of genes underpinning seeding root system traits [84] in wheat. However, GiA Roots has slowly been rendered outdated by new software tools such as Digital Imaging of Root Traits (DIRT) [85] and the neural network driven programs SegRoot [86] and saRIA [87], described below.

DIRT is a unique web platform backed by a computing cluster for the processing of image data $[85,88,89]$. Furthermore, this platform is unique in that it hosts a growing collection of public image sets shared by researchers around the globe [85]. The DIRT platform quantifies root system architectural traits such as width accumulation, spatial distribution, and rooting angles in batches of images uploaded to the online interface. DIRT was designed to process images of excised roots taken with low-cost imaging systems (such as tripod-mounted smartphones) in a field setting. The use of scale markers in the images enables DIRT to correct for camera tilting and to set the scale for each image without user intervention $[85,88,89]$. DIRT offers promise to wheat research due to its unique ability to quantify excised root systems without the need for added technical training required for installing and running standalone software. The DIRT platform has already been used to explore wheat's response to phosphorous deficiency [90]. To date, many wheat image collections exist on the DIRT platform, raising promise for its future usage in wheat research.

\subsection{Recent Advances in Root Phenotyping Using Deep Learning}

The semi-automated saRIA [87] and the fully automated SegRoot [86] are recently published tools that can quantify useful traits in wheat root systems. Each of these tools was trained using a convolutional neural network ( $\mathrm{CNN})$ to identify roots in visually noisy images [45]. The semi-automated saRIA was developed in MatLab (MathWorks, Natick, MA, USA) and computes a suite of traits from roots grown in agar, fine soil, or other media with shapes that differ sufficiently from the roots being studied [87]. Some room for machine error is given when using saRIA, as the user has the option to remove objects that have been mis-identified as roots in the image. SegRoot is fully automated and has its output traits limited only to length. However, SegRoot has a very low image quality requirement in that it is amenable to analyzing roots from complex, visually heterogeneous soil backgrounds [86]. Both SegRoot and saRIA were tested for accuracy against other published tools, and both outperformed GiA Roots in the identification of roots in heterogeneous growth media, demonstrating clear benefits of machine learning-informed approaches in root phenotyping. These tools have promise for rapidly identifying wheat roots imaged in soil-bound systems, such as minirhizotrons and rhizotrons, without the need for manual image pre-processing with image manipulation software. This is especially important, as it opens the door to the analysis of more mature root systems, expanding the scope of wheat root phenotyping away from the limited architectures of seedlings to those of mature plants.

\subsection{Research Trajectories in Root Phenotyping}

Phenotyping under controlled conditions has brought a notable number of studies that assay wheat seedling traits prior to transplantation $[73,74,91]$, which has produced datasets of traits that are correlative of yield components in wheat. Outdoor rhizotrons enable measurements of soil-bound roots in an environment that simulates field soil [52,92]. Minirhizotrons can be used to assay root turnover of plants in field soil, which can generate informative phenotypes of individual plants or of several individuals of the same genotype sown in close proximity $[53,93]$. Excavation-based shovelomics approaches can provide the throughput needed in a field setting to overcome the variability inherent in root phenotyping by virtue of their low equipment requirement and relatively simple procedure [50]. Shovelomics and its accompanying software tools (REST [94], DIRT [85]) collectively enable root phenotyping at scale in the field. Though full excavation becomes impossible for mature plants, the correlative traits derived from immature root systems or from mature root crowns remove the confounding factor of having a controlled environment. This potentially allows them to be more indicative of mature plant phenotypes for breeding or of underlying plant physiology for research. 
Overall, the needs of the wheat research community for root phenotyping are increasingly being met with the collection of physical tools and the development of effective imaging tools [30].

\section{Phenotyping of Seed Traits}

\subsection{Challenges and Software Applicable to Seed Phenotyping in Wheat}

Wheat is grown almost exclusively for grain consumption. The yield of wheat has an obvious interplay with grain-centered phenotypes such as seed number, shape, and size. Grain color is also relevant as it may influence consumer preference of end-use products [95]. Despite the importance of seed phenotypes to wheat cultivation and marketing, phenotyping of wheat seed is limited by a pair of factors. Firstly, seeds are small and variable in size, requiring a high number of careful dimensional measurements to successfully capture the trends in seed characteristics across cultivars or populations [96]. Secondly, robust measurements of seed color are difficult or impossible to make by human estimation. To circumvent the issue of throughput and color phenotyping, several image-based tools have emerged in the last 20 years that can enable rapid quantification of seed dimensions and colors. There is currently a pair of publicly available software tools, as well as a pair of proprietary, hardware-specific tools, available to researchers for seed phenotyping (Table 3).

Table 3. Commonly used image-based tools for seed phenotyping in wheat.

\begin{tabular}{cccccc}
\hline Software & $\begin{array}{c}\text { Software/ } \\
\text { Hardware Cost }\end{array}$ & $\begin{array}{c}\text { Open } \\
\text { Source }\end{array}$ & $\begin{array}{c}\text { Operating } \\
\text { System }\end{array}$ & Automation & Example Output Trait \\
\hline SmartGrain & No & No & Windows XP+ & Semi-automated & $\begin{array}{c}\text { Seed size, dimensions, } \\
\text { seed count }\end{array}$ \\
\hline GrainScan & No & No & Windows 7+ & $\begin{array}{c}\text { Fully } \\
\text { automated }\end{array}$ & $\begin{array}{c}\text { Seed size, dimensions, } \\
\text { color, seed count }\end{array}$ \\
\hline WinSEEDLE & Yes & No & Windows 7+ & $\begin{array}{c}\text { Fully } \\
\text { automated }\end{array}$ & $\begin{array}{c}\text { Seed size, dimensions, } \\
\text { color, curvature, count }\end{array}$ \\
\hline SeedCount & Yes & No & Windows 7 & $\begin{array}{c}\text { Fully } \\
\text { automated }\end{array}$ & $\begin{array}{c}\text { Seed size, dimensions, } \\
\text { color, seed count }\end{array}$ \\
\hline
\end{tabular}

SmartGrain [97] and GrainScan [96] are independent of specialized hardware and can be used with low-cost, conventional flatbed document scanners. SmartGrain analyzes seed size and dimensions for each grain in the image, effectively giving the seed count [97]. SmartGrain is semi-automated in the sense that the user needs to review and potentially correct the masking of the grains from the background to ensure that they were detected properly. GrainScan is fully automated and analyzes seed size and dimensions while also taking standardized color measurements [96]. Although GrainScan is equipped with batch processing and tunable thresholding parameters, it does not offer manual correction by the user. Both packages have been widely employed in wheat research. SmartGrain has been leveraged to explore the genetics underlying yield components [98-102], to aid breeding and introgression [103-105], and to analyze drought response [106]. GrainScan has been used in the exploration of yield genetics $[107,108]$, the evaluation of ancestral germplasm [109], and in the unraveling of wheat domestication [110]. Both of the phenotyping tools noted here could see broad implementation in academic laboratories, as they have low equipment requirements and require little advanced technical expertise to operate.

The proprietary phenotyping platforms, WinSEEDLE (Regent Instruments, Quebec City, QC, Canada) and SeedCount (Next Instruments, Condell Park, Australia), are associated with specialized hardware that comes as an extra expense for researchers. In both cases, this specialized hardware functions to increase throughput and image quality relative to conventional flatbed scanners. Both WinSEEDLE and SeedCount are fully automated and provide information about seed shape, number, and color. These systems predate the freeware outlined above and have been applied in many 
studies since their release. Like GrainScan and SmartGrain, WinSEEDLE has been used in explorations of genetic and phenotypic underpinnings of yield components in wheat [111-116]. SeedCount has seen broad use in academic research. In addition to usage in genetic mapping studies for yield [117-119], SeedCount has been leveraged to explore wheat abiotic stress response [120-122], grain mineral accumulation [118,123-125], and to evaluate germplasm [126,127]. Usage of these proprietary tools certainly extends beyond what is reported in academic literature. The marketing of these proprietary platforms is primarily directed toward seed industry professionals. As such, applications in the public domain represent only a subset of their overall usage. Nonetheless, there are clear avenues for usage of these proprietary seed phenotyping tools in academic research, provided that their cost is not prohibitive.

\subsection{Research Trajectories in Seed Phenotyping}

Compared to images of shoots and roots, the images of seeds are less complex in terms of the identification of individual seeds and to the number of informative phenotypes that can be garnered from these seeds. Discrepancies in seed size are detected readily by gravimetric measurements while clear discrepancies in seed shape across varieties are often not quantified. However, phenotypes that are difficult or arduous to assay by hand such as color or seed count are quickly measured by image analysis using aforementioned tools. Improvements in this space could stand to leverage recent advances in deep learning and image analysis to enable more reliable identification of seeds against a wider range of image backgrounds, namely light-colored or textured backgrounds with low contrast to the seeds [128]. Increasing robustness of seed identification across many backgrounds could expand the currently limited collection of mobile applications for seed phenotyping, which are currently limited to seed counting [129], by supplying tools capable of measuring dimensions and shape from smartphone images. Such improvements have the potential to supplant the need for scanning devices when phenotyping wheat grains, much like the portable apps that are becoming increasingly germane to shoot phenotyping.

\section{Concluding Remarks and Future Perspectives}

A suite of accessible phenotyping tools has been developed that is applicable to both fundamental and applied wheat research. An integrated phenotyping approach that accounts for many aspects of plant growth can unravel the effects of genetics, environmental factors, and management practices on the physiology of wheat and ultimately translate this to enhancing its performance and productivity in the field. Rapid, comprehensive evaluation of wheat at varying stages in the breeding pipeline-from wild species to landraces to elite breeding lines-will be instrumental in increasing wheat yields to accommodate the increase in the demand for wheat that comes with a rapidly growing world population. Moreover, the increasing accessibility of these tools, particularly for shoot and seed phenotyping, has resulted in lower learning curves and imaging requirements so that a wider range of breeders can rise to meet this global need without being required to reinvent their breeding pipelines.

Research trajectories for shoot, root, and seed phenotyping in wheat, and in crops in general, are discussed in the above sections. Looking forward, several developments will continue to improve the throughput, accuracy, and accessibility of the phenotyping outlined here. From the biological sciences, advances in next-generation sequencing, genetic, and functional genomic analyses collectively improve our ability to leverage phenotypic observations to explore the idiosyncrasies of the wheat genome and to develop new cultivars. From the engineering and computational sciences, the software and hardware tools available for this effort will steadily improve as well; breakthroughs in deep learning, computer vision, and graphical user interfaces are being complemented by advances in image acquisition and computing clusters. The continued collaborative efforts among these disciplines hold promise to generate a wealth of phenotyping data readily accessible for analysis by researchers in basic and applied sciences, much like wealth of genetic information that already exists publicly 
for wheat [130]. The expansion of phenotyping information will facilitate multidisciplinary research investigations in wheat that enable us to hit the needed yield benchmarks for decades to come.

Author Contributions: Conceptualization, C.S.B. and L.T.; Writing-Original Draft Preparation, C.S.B. and J.H.; Writing-Review and Editing, C.S.B. and L.T.; Supervision, L.T. All authors have read and agreed to the published version of the manuscript.

Funding: This research was funded by the United States Department of Agriculture - National Institute of Food and Agriculture, grant number 2017-67013-26164 to L.T.

Conflicts of Interest: The authors declare no conflict of interest.

\section{References}

1. International Maize and Wheat Improvement Center. Wheat Research. Available online: https://www. cimmyt.org/work/wheat-research/ (accessed on 11 June 2020).

2. Fiorani, F.; Schurr, U. Future scenarios for plant phenotyping. Annu. Rev. Plant Biol. 2013, 64, $267-291$. [CrossRef] [PubMed]

3. Lynch, J.P. Root phenes for enhanced soil exploration and phosphorus acquisition: Tools for future crops. Plant Physiol. 2011, 156, 1041-1049. [CrossRef] [PubMed]

4. Tardieu, F.; Cabrera-Bosquet, L.; Pridmore, T.; Bennett, M. Plant phenomics, from sensors to knowledge. Curr. Biol. 2017, 27, R770-R783. [CrossRef] [PubMed]

5. Roitsch, T.; Cabrera-Bosquet, L.; Fournier, A.; Ghamkhar, K.; Jiménez-Berni, J.; Pinto, F.; Ober, E.S. Review: New sensors and data-driven approaches-A path to next generation phenomics. Plant Sci. 2019, 282, 2-10. [CrossRef] [PubMed]

6. Furbank, R.T.; Tester, M. Phenomics-technologies to relieve the phenotyping bottleneck. Trends Plant Sci. 2011, 16, 635-644. [CrossRef]

7. Abramoff, M.; Magalhães, P.; Ram, S. Image processing with ImageJ. Biophotonics Int. 2004, 11, 36-42.

8. Maloof, J.N.; Nozue, K.; Mumbach, M.R.; Palmer, C.M. LeafJ: An ImageJ plugin for semi-automated leaf shape measurement. J. Vis. Exp. 2013, e50028. [CrossRef]

9. Panwar, V.; McCallum, B.; Bakkeren, G. Host-induced gene silencing of wheat leaf rust fungus Puccinia triticina pathogenicity genes mediated by the Barley stripe mosaic virus. Plant Mol. Biol. 2013, 81, 595-608. [CrossRef]

10. Lobet, G.; Draye, X.; Périlleux, C. An online database for plant image analysis software tools. Plant Methods 2013, 9, 38. [CrossRef]

11. Easlon, H.M.; Bloom, A.J. Easy Leaf Area: Automated digital image analysis for rapid and accurate measurement of leaf area. Appl. Plant Sci. 2014, 2, 1400033. [CrossRef]

12. Anderson, C.J.R.; Rosas-Anderson, P.J. Leafscan. Available online: http://www.leafscanapp.com/ (accessed on 12 July 2020).

13. Müller-Linow, M.; Wilhelm, J.; Briese, C.; Wojciechowski, T.; Schurr, U.; Fiorani, F. Plant Screen Mobile: An open-source mobile device app for plant trait analysis. Plant Methods 2019, 15, 2. [CrossRef] [PubMed]

14. Dornbusch, T.; Andrieu, B. Lamina2Shape-An image processing tool for an explicit description of lamina shape tested on winter wheat (Triticum aestivum L.). Comput. Electron. Agric. 2010, 70, 217-224. [CrossRef]

15. Abichou, M.; de Solan, B.; Andrieu, B. Architectural response of wheat cultivars to row spacing reveals altered perception of plant density. Front. Plant Sci. 2019, 10, 999. [CrossRef] [PubMed]

16. Dornbusch, T.; Baccar, R.; Watt, J.; Hillier, J.; Bertheloot, J.; Fournier, C.; Andrieu, B. Plasticity of winter wheat modulated by sowing date, plant population density and nitrogen fertilisation: Dimensions and size of leaf blades, sheaths and internodes in relation to their position on a stem. Field Crops Res. 2011, 121, 116-124. [CrossRef]

17. Yang, Y.; Ni, X.; Zhou, Z.; Yu, L.; Liu, B.; Yang, Y.; Wu, Y. Performance of matrix-based slow-release urea in reducing nitrogen loss and improving maize yields and profits. Field Crops Res. 2017, 212, 73-81. [CrossRef]

18. Cowley, T.; Walters, D. Local and systemic effects of oxylipins on powdery mildew infection in barley. Pest Manag. Sci. 2005, 61, 572-576. [CrossRef] [PubMed] 
19. Machado, B.B.; Orue, J.P.M.; Arruda, M.S.; Santos, C.V.; Sarath, D.S.; Goncalves, W.N.; Silva, G.G.; Pistori, H.; Roel, A.R.; Rodrigues, J.F., Jr. BioLeaf: A professional mobile application to measure foliar damage caused by insect herbivory. Comput. Electron. Agric. 2016, 129, 44-55. [CrossRef]

20. Getman-Pickering, Z.L.; Campbell, A.; Aflitto, N.C.; Ugine, T.A.; Grele, A.; Davis, J.K. LeafByte: A mobile application that measures leaf area and herbivory quickly and accurately. Methods Ecol. Evol. 2020, 11, 215-221. [CrossRef]

21. Pethybridge, S.J.; Nelson, S.C. Leaf Doctor: A new portable application for quantifying plant disease severity. Plant Dis. 2015, 99, 1310-1316. [CrossRef]

22. Saari, E.; Prescott, J. A scale for appraising the foliar intensity of wheat diseases. Plant Dis. Rep. 1975, 59, 377-380.

23. Hartmann, A.; Czauderna, T.; Hoffmann, R.; Stein, N.; Schreiber, F. HTPheno: An image analysis pipeline for high-throughput plant phenotyping. BMC Bioinform. 2011, 12, 148. [CrossRef] [PubMed]

24. Nakhforoosh, A.; Bodewein, T.; Fiorani, F.; Bodner, G. Identification of water use strategies at early growth stages in durum wheat from shoot phenotyping and physiological measurements. Front. Plant Sci. 2016, 7, 1155. [CrossRef] [PubMed]

25. Merchuk-Ovnat, L.; Ovnat, Z.; Amir-Segev, O.; Kutsher, Y.; Saranga, Y.; Reuveni, M. CoverageTool: A semi-automated graphic software: Applications for plant phenotyping. Plant Methods 2019, 15, 90. [CrossRef] [PubMed]

26. Pound, M.P.; French, A.P.; Murchie, E.H.; Pridmore, T.P. Automated recovery of three-dimensional models of plant shoots from multiple color images. Plant Physiol. 2014, 166, 1688-1698. [CrossRef] [PubMed]

27. Pieruschka, R.; Schurr, U. Plant phenotyping: Past, present, and future. Plant Phenom. 2019, $2019,6$. [CrossRef]

28. Reynolds, M.; Foulkes, J.; Furbank, R.; Griffiths, S.; King, J.; Murchie, E.; Parry, M.; Slafer, G. Achieving yield gains in wheat. Plant Cell Environ. 2012, 35, 1799-1823. [CrossRef]

29. Patrignani, A.; Ochsner, T.E. Canopeo: A powerful new tool for measuring fractional green canopy cover. Agron. J. 2015, 107, 2312-2320. [CrossRef]

30. Lobet, G. Image analysis in plant sciences: Publish then perish. Trends Plant Sci. 2017, 22, 559-566. [CrossRef]

31. Shaw, G.; Burke, H. Spectral imaging for remote sensing. MIT Linc. Lab. J. 2003, 14, 3-28.

32. Xue, J.; Su, B. Significant remote sensing vegetation indices: A review of developments and applications. J. Sens. 2017, 2017, 1353691. [CrossRef]

33. Rouse, J.; Haas, J.; Schell, J.; Deering, D. Monitoring vegetation systems in the Great Plains with ERTS. In Third Earth Resources Technology Satellite-1 Symposium; NASA SP-351; NASA Goddard Space Flight Center: Greenbelt, MD, USA, 1974; pp. 301-317.

34. Magney, T.S.; Eitel, J.U.H.; Huggins, D.R.; Vierling, L.A. Proximal NDVI derived phenology improves in-season predictions of wheat quantity and quality. Agric. For. Meteorol. 2016, 217, 46-60. [CrossRef]

35. Robinson, N.A.; Sheedy, J.G.; MacDonald, B.J.; Owen, K.J.; Thompson, J.P. Tolerance of wheat cultivars to root-lesion nematode (Pratylenchus thornei) assessed by normalised difference vegetation index is predictive of grain yield. Ann. Appl. Biol. 2019, 174, 388-401. [CrossRef]

36. Honsdorf, N.; Verhulst, N.; Crossa, J.; Vargas, M.; Govaerts, B.; Ammar, K. Durum wheat selection under zero tillage increases early vigor and is neutral to yield. Field Crops Res. 2020, 248, 107675. [CrossRef]

37. Bennett, D.; Reynolds, M.; Mullan, D.; Izanloo, A.; Kuchel, H.; Langridge, P.; Schnurbusch, T. Detection of two major grain yield QTL in bread wheat (Triticum aestivum L.) under heat, drought and high yield potential environments. Theor. Appl. Genet. 2012, 125, 1473-1485. [CrossRef]

38. Babar, M.A.; van Ginkel, M.; Klatt, A.R.; Prasad, B.; Reynolds, M.P. The potential of using spectral reflectance indices to estimate yield in wheat grown under reduced irrigation. Euphytica 2006, 150, 155-172. [CrossRef]

39. Devadas, R.; Lamb, D.W.; Simpfendorfer, S.; Backhouse, D. Evaluating ten spectral vegetation indices for identifying rust infection in individual wheat leaves. Precis. Agric. 2009, 10, 459-470. [CrossRef]

40. Babar, M.A.; Reynolds, M.P.; Van Ginkel, M.; Klatt, A.R.; Raun, W.R.; Stone, M.L. Spectral reflectance to estimate genetic variation for in-season biomass, leaf chlorophyll, and canopy temperature in wheat. Crop Sci. 2006, 46, 1046-1057. [CrossRef]

41. Prey, L.; Hu, Y.; Schmidhalter, U. High-throughput field phenotyping traits of grain yield formation and nitrogen use efficiency: Optimizing the selection of vegetation indices and growth stages. Front. Plant Sci. 2020, 10, 1672. [CrossRef] 
42. Bruning, B.; Berger, B.; Lewis, M.; Liu, H.; Garnett, T. Approaches, applications, and future directions for hyperspectral vegetation studies: An emphasis on yield-limiting factors in wheat. Plant Phenome J. 2020, 3, e20007. [CrossRef]

43. Chawade, A.; van Ham, J.; Blomquist, H.; Bagge, O.; Alexandersson, E.; Ortiz, R. High-throughput field-phenotyping tools for plant breeding and precision agriculture. Agronomy 2019, 9, 258. [CrossRef]

44. Ceccarelli, S.; Grando, S. Decentralized-participatory plant breeding: An example of demand driven research. Euphytica 2007, 155, 349-360. [CrossRef]

45. Pound, M.P.; Atkinson, J.A.; Townsend, A.J.; Wilson, M.H.; Griffiths, M.; Jackson, A.S.; Bulat, A.; Tzimiropoulos, G.; Wells, D.M.; Murchie, E.H.; et al. Deep machine learning provides state-of-the-art performance in image-based plant phenotyping. GigaScience 2017, 6, 1-10. [CrossRef] [PubMed]

46. Alkhudaydi, T.; Reynolds, D.; Griffiths, S.; Zhou, J.; de la Iglesia, B. An exploration of deep-learning based phenotypic analysis to detect spike regions in field conditions for UK bread wheat. Plant Phenom. 2019, 2019, 17. [CrossRef]

47. Lynch, J.M.; Whipps, J.M. Substrate flow in the rhizosphere. Plant Soil 1990, 129, 1-10. [CrossRef]

48. Lynch, J. Root architecture and plant productivity. Plant Physiol. 1995, 109, 7-13. [CrossRef]

49. Armengaud, P. EZ-Rhizo software: The gateway to root architecture analysis. Plant Signal. Behav. 2009, 4, 139-141. [CrossRef]

50. Trachsel, S.; Kaeppler, S.M.; Brown, K.M.; Lynch, J.P. Shovelomics: High throughput phenotyping of maize (Zea mays L.) root architecture in the field. Plant Soil 2011, 341, 75-87. [CrossRef]

51. Volder, A.; Van Iersel, M. Root growth, physiology, and potential impact of soilless culture on their functioning. In Soilless Culture: Theory and Practice; Raviv, M., Lieth, J., Bar-Tal, A., Eds.; Elsevier: Amsterdam, The Netherlands, 2019; pp. 15-32.

52. Huck, M.G.; Taylor, H.M. The rhizotron as a tool for root research. Adv. Agron. 1982, 35, 1-35.

53. Brown, D.; Upchurch, D. Minirhizotrons: A summary of methods and instruments in current use. In Minirhizotron Observation Tubes: Methods and Applications for Measuring Rhizosphere Dynamics; Taylor, H., Ed.; John Wiley \& Sons, Ltd.: Hoboken, NJ, USA, 2015; pp. 15-30.

54. Mooney, S.J.; Pridmore, T.P.; Helliwell, J.; Bennett, M.J. Developing X-ray Computed Tomography to non-invasively image 3-D root systems architecture in soil. Plant Soil 2012, 352, 1-22. [CrossRef]

55. Kaspar, T.C.; Ewing, R.P. ROOTEDGE: Software for measuring root length from desktop scanner images. Agron. J. 1997, 89, 932-940. [CrossRef]

56. Himmelbauer, M.L.; Loiskandl, A.W.; Kastanek, A.F. Estimating length, average diameter and surface area of roots using two different Image analyses systems. Plant Soil 2004, 260, 111-120. [CrossRef]

57. Zuo, Q.; Jie, F.; Zhang, R.; Meng, L. A generalized function of wheat's root length density distributions. Vadose Zone J. 2004, 3, 271-277. [CrossRef]

58. Nuruzzaman, M.; Lambers, H.; Bolland, M.D.A.; Veneklaas, E.J. Phosphorus benefits of different legume crops to subsequent wheat grown in different soils of Western Australia. Plant Soil 2005, 271, 175-187. [CrossRef]

59. Ren, Y.; He, X.; Liu, D.; Li, J.; Zhao, X.; Li, B.; Tong, Y.; Zhang, A.; Li, Z. Major quantitative trait loci for seminal root morphology of wheat seedlings. Mol. Breed. 2012, 30, 139-148. [CrossRef]

60. Bai, C.; Liang, Y.; Hawkesford, M.J. Identification of QTLs associated with seedling root traits and their correlation with plant height in wheat. J. Exp. Bot. 2013, 64, 1745-1753. [CrossRef] [PubMed]

61. Liu, X.; Li, R.; Chang, X.; Jing, R. Mapping QTLs for seedling root traits in a doubled haploid wheat population under different water regimes. Euphytica 2013, 189, 51-66. [CrossRef]

62. Flavel, R.J.; Guppy, C.N.; Tighe, M.K.; Watt, M.; Young, I.M. Quantifying the response of wheat (Triticum aestivum L) root system architecture to phosphorus in an Oxisol. Plant Soil 2014, 385, 303-310. [CrossRef]

63. Wang, Y.; Thorup-Kristensen, K.; Jensen, L.S.; Magid, J. Vigorous root growth is a better indicator of early nutrient uptake than root hair traits in spring wheat grown under low fertility. Front. Plant Sci. 2016, 7, 865. [CrossRef]

64. Olmo, M.; Villar, R.; Salazar, P.; Alburquerque, J.A. Changes in soil nutrient availability explain biochar's impact on wheat root development. Plant Soil 2016, 399, 333-343. [CrossRef]

65. Manschadi, A.; Christopher, J.; deVoil, P.; Hammer, G. The role of root architectural traits in adaptation of wheat to water-limited environments. Funct. Plant Biol. 2006, 33, 823-837. [CrossRef] 
66. Kirkegaard, J.A.; Lilley, J.M.; Howe, G.N.; Graham, J.M. Impact of subsoil water use on wheat yield. Aust. J. Agric. Res. 2007, 58, 303-315. [CrossRef]

67. Narayanan, S.; Mohan, A.; Gill, K.S.; Prasad, P.V.V. Variability of root traits in spring wheat germplasm. PLoS ONE 2014, 9, e100317. [CrossRef] [PubMed]

68. Lobet, G.; Pagès, L.; Draye, X. A novel image-analysis toolbox enabling quantitative analysis of root system architecture. Plant Physiol. 2011, 157, 29-39. [CrossRef] [PubMed]

69. Pound, M.P.; French, A.P.; Atkinson, J.A.; Wells, D.M.; Bennett, M.J.; Pridmore, T. RootNav: Navigating images of complex root architectures. Plant Physiol. 2013, 162, 1802-1814. [CrossRef] [PubMed]

70. Roselló, M.; Royo, C.; Sanchez-Garcia, M.; Soriano, J. Genetic dissection of the seminal root system architecture in Mediterranean durum wheat landraces by genome-wide association study. Agronomy 2019, 9, 364. [CrossRef]

71. Ruiz, M.; Giraldo, P.; González, J.M. Phenotypic variation in root architecture traits and their relationship with eco-geographical and agronomic features in a core collection of tetraploid wheat landraces (Triticum turgidum L.). Euphytica 2018, 214, 54. [CrossRef]

72. Finch, J.A.; Guillaume, G.; French, S.A.; Colaço, R.D.D.R.; Davies, J.M.; Swarbreck, S.M. Wheat root length and not branching is altered in the presence of neighbours, including blackgrass. PLOS ONE 2017, 12, e0178176. [CrossRef]

73. Canè, M.A.; Maccaferri, M.; Nazemi, G.; Salvi, S.; Francia, R.; Colalongo, C.; Tuberosa, R. Association mapping for root architectural traits in durum wheat seedlings as related to agronomic performance. Mol. Breed. 2014, 34, 1629-1645. [CrossRef]

74. Xie, Q.; Fernando, K.M.C.; Mayes, S.; Sparkes, D.L. Identifying seedling root architectural traits associated with yield and yield components in wheat. Ann. Bot. 2017, 119, 1115-1129. [CrossRef]

75. Kenobi, K.; Atkinson, J.A.; Wells, D.M.; Gaju, O.; De Silva, J.G.; Foulkes, M.J.; Dryden, I.L.; Wood, A.T.A.; Bennett, M.J. Linear discriminant analysis reveals differences in root architecture in wheat seedlings related to nitrogen uptake efficiency. J. Exp. Bot. 2017, 68, 4969-4981. [CrossRef]

76. Shorinola, O.; Kaye, R.; Golan, G.; Peleg, Z.; Kepinski, S.; Uauy, C. Genetic screening for mutants with altered seminal root numbers in hexaploid wheat using a high-throughput root phenotyping platform. G3 Genes Genom. Genet. 2019, 9, 2799-2809. [CrossRef] [PubMed]

77. Griffiths, M.; Atkinson, J.; Gardiner, L.-J.; Swarup, R.; Pound, M.; Wilson, M.; Bennett, M.; Wells, D. Identification of nitrogen-dependent QTL and underlying genes for root system architecture in hexaploid wheat. bioRxiv 2019, 591529. [CrossRef]

78. Atkinson, J.A.; Wingen, L.U.; Griffiths, M.; Pound, M.P.; Gaju, O.; Foulkes, M.J.; Le Gouis, J.; Griffiths, S.; Bennett, M.J.; King, J.; et al. Phenotyping pipeline reveals major seedling root growth QTL in hexaploid wheat. J. Exp. Bot. 2015, 66, 2283-2292. [CrossRef] [PubMed]

79. Yasrab, R.; Atkinson, J.A.; Wells, D.M.; French, A.P.; Pridmore, T.P.; Pound, M.P. RootNav 2.0: Deep learning for automatic navigation of complex plant root architectures. GigaScience 2019, 8, 1-16. [CrossRef] [PubMed]

80. Galkovskyi, T.; Mileyko, Y.; Bucksch, A.; Moore, B.; Symonova, O.; Price, C.A.; Topp, C.N.; Iyer-Pascuzzi, A.S.; Zurek, P.R.; Fang, S.; et al. GiA Roots: Software for the high throughput analysis of plant root system architecture. BMC Plant Biol. 2012, 12, 116. [CrossRef]

81. Ahmadi, J.; Pour-Aboughadareh, A.; Fabriki-Ourang, S.; Mehrabi, A.-A.; Siddique, K.H.M. Screening wheat germplasm for seedling root architectural traits under contrasting water regimes: Potential sources of variability for drought adaptation. Arch. Agron. Soil Sci. 2018, 64, 1351-1365. [CrossRef]

82. Alahmad, S.; El Hassouni, K.; Bassi, F.M.; Dinglasan, E.; Youssef, C.; Quarry, G.; Aksoy, A.; Mazzucotelli, E.; Juhász, A.; Able, J.A.; et al. A major root architecture QTL responding to water limitation in durum wheat. Front. Plant Sci. 2019, 10, 436. [CrossRef]

83. Llorens, E.; Sharon, O.; Camañes, G.; García-Agustín, P.; Sharon, A. Endophytes from wild cereals protect wheat plants from drought by alteration of physiological responses of the plants to water stress. Environ. Microbiol. 2019, 21, 3299-3312. [CrossRef]

84. Voss-Fels, K.P.; Qian, L.; Parra-Londono, S.; Uptmoor, R.; Frisch, M.; Keeble-Gagnère, G.; Appels, R.; Snowdon, R.J. Linkage drag constrains the roots of modern wheat. Plant Cell Environ. 2017, 40, 717-725. [CrossRef] 
85. Das, A.; Schneider, H.; Burridge, J.; Ascanio, A.K.M.; Wojciechowski, T.; Topp, C.N.; Lynch, J.P.; Weitz, J.S.; Bucksch, A. Digital imaging of root traits (DIRT): A high-throughput computing and collaboration platform for field-based root phenomics. Plant Methods 2015, 11, 51. [CrossRef]

86. Wang, T.; Rostamza, M.; Song, Z.; Wang, L.; McNickle, G.; Iyer-Pascuzzi, A.S.; Qiu, Z.; Jin, J. SegRoot: A high throughput segmentation method for root image analysis. Comput. Electron. Agric. 2019, 162, 845-854. [CrossRef]

87. Narisetti, N.; Henke, M.; Seiler, C.; Shi, R.; Junker, A.; Altmann, T.; Gladilin, E. Semi-automated Root Image Analysis (saRIA). Sci. Rep. 2019, 9, 19674. [CrossRef] [PubMed]

88. Bucksch, A.; Burridge, J.; York, L.M.; Das, A.; Nord, E.; Weitz, J.S.; Lynch, J.P. Image-based high-throughput field phenotyping of crop roots. Plant Physiol. 2014, 166, 470-486. [CrossRef] [PubMed]

89. Stanzione, D. The iPlant collaborative: Cyberinfrastructure to feed the world. Computer 2011, 44, 44-52. [CrossRef]

90. Nguyen, V.L.; Stangoulis, J. Variation in root system architecture and morphology of two wheat genotypes is a predictor of their tolerance to phosphorus deficiency. Acta Physiol. Plant. 2019, 41, 109. [CrossRef]

91. Watt, M.; Moosavi, S.; Cunningham, S.C.; Kirkegaard, J.A.; Rebetzke, G.J.; Richards, R.A. A rapid, controlled-environment seedling root screen for wheat correlates well with rooting depths at vegetative, but not reproductive, stages at two field sites. Ann. Bot. 2013, 112, 447-455. [CrossRef]

92. Mohamed, A.; Monnier, Y.; Mao, Z.; Lobet, G.; Maeght, J.-L.; Ramel, M.; Stokes, A. An evaluation of inexpensive methods for root image acquisition when using rhizotrons. Plant Methods 2017, 13, 11. [CrossRef]

93. Postic, F.; Beauchêne, K.; Gouache, D.; Doussan, C. Scanner-based minirhizotrons help to highlight relations between deep roots and yield in various wheat cultivars under combined water and nitrogen deficit conditions. Agronomy 2019, 9, 297. [CrossRef]

94. Colombi, T.; Kirchgessner, N.; Le Marié, C.A.; York, L.M.; Lynch, J.P.; Hund, A. Next generation shovelomics: Set up a tent and REST. Plant Soil 2015, 388, 1-20. [CrossRef]

95. Challacombe, C.A.; Seetharaman, K.; Duizer, L.M. Sensory characteristics and consumer acceptance of bread and cracker products made from red or white wheat. J. Food Sci. 2011, 76, S337-S346. [CrossRef]

96. Whan, A.P.; Smith, A.B.; Cavanagh, C.R.; Ral, J.-P.F.; Shaw, L.M.; Howitt, C.A.; Bischof, L. GrainScan: A low cost, fast method for grain size and colour measurements. Plant Methods 2014, 10, 23. [CrossRef] [PubMed]

97. Tanabata, T.; Shibaya, T.; Hori, K.; Ebana, K.; Yano, M. SmartGrain: High-throughput phenotyping software for measuring seed shape through image analysis. Plant Physiol. 2012, 160, 1871-1880. [CrossRef] [PubMed]

98. Okamoto, Y.; Nguyen, A.T.; Yoshioka, M.; Iehisa, J.C.M.; Takumi, S. Identification of quantitative trait loci controlling grain size and shape in the D genome of synthetic hexaploid wheat lines. Breed. Sci. 2013, 63, 423-429. [CrossRef] [PubMed]

99. Sestili, F.; Pagliarello, R.; Zega, A.; Saletti, R.; Pucci, A.; Botticella, E.; Masci, S.; Tundo, S.; Moscetti, I.; Foti, S.; et al. Enhancing grain size in durum wheat using RNAi to knockdown GW2 genes. Theor. Appl. Genet. 2019, 132, 419-429. [CrossRef]

100. Kumari, S.; Mir, R.R.; Tyagi, S.; Balyan, H.S.; Gupta, P.K. Validation of QTL for grain weight using MAS-derived pairs of NILs in bread wheat (Triticum aestivum L.). J. Plant Biochem. Biot. 2019, 28, 336-344. [CrossRef]

101. Yoshioka, M.; Takenaka, S.; Nitta, M.; Li, J.; Mizuno, N.; Nasuda, S. Genetic dissection of grain morphology in hexaploid wheat by analysis of the NBRP-Wheat core collection. Genes Genet. Syst. 2019, 94, 35-49. [CrossRef]

102. Kumari, S.; Jaiswal, V.; Mishra, V.K.; Paliwal, R.; Balyan, H.S.; Gupta, P.K. QTL mapping for some grain traits in bread wheat (Triticum aestivum L.). Physiol. Mol. Biol. Plants 2018, 24, 909-920. [CrossRef]

103. Sakai, Y.; Cao, L.; Funata, R.; Shiraishi, T.; Yoshikawa, K.; Maeno, K.; Miura, H.; Onishi, K. QTLs for agronomic traits detected in recombinant inbred lines derived from a bread wheat $\times$ spelt cross. Breed. Sci. 2018, 68, 587-595. [CrossRef]

104. Okada, M.; Michikawa, A.; Yoshida, K.; Nagaki, K.; Ikeda, T.M.; Takumi, S. Phenotypic effects of the U-genome variation in nascent synthetic hexaploids derived from interspecific crosses between durum wheat and its diploid relative Aegilops umbellulata. PLOS ONE 2020, 15, e231129. [CrossRef]

105. Takumi, S.; Mitta, S.; Komura, S.; Ikeda, T.M.; Matsunaka, H.; Sato, K.; Yoshida, K.; Murai, K. Introgression of chromosomal segments conferring early heading date from wheat diploid progenitor, Aegilops tauschii Coss., into Japanese elite wheat cultivars. PLOS ONE 2020, 15, e0228397. [CrossRef] 
106. Abid, M.; Shao, Y.; Liu, S.; Wang, F.; Gao, J.; Jiang, D.; Tian, Z.; Dai, T. Pre-drought priming sustains grain development under post-anthesis drought stress by regulating the growth hormones in winter wheat (Triticum aestivum L.). Planta 2017, 246, 509-524. [CrossRef] [PubMed]

107. Bowerman, A.F.; Newberry, M.; Dielen, A.-S.; Whan, A.; Larroque, O.; Pritchard, J.; Gubler, F.; Howitt, C.A.; Pogson, B.J.; Morell, M.K.; et al. Suppression of glucan, water dikinase in the endosperm alters wheat grain properties, germination and coleoptile growth. Plant Biotechnol. J. 2016, 14, 398-408. [CrossRef] [PubMed]

108. Alemu, A.; Feyissa, T.; Tuberosa, R.; Maccaferri, M.; Sciara, G.; Letta, T.; Abeyo, B. Genome-wide association mapping for grain shape and color traits in Ethiopian durum wheat (Triticum turgidum ssp. durum). Crop J. 2020. [CrossRef]

109. Kehel, Z.; Sanchez-Garcia, M.; El Baouchi, A.; Aberkane, H.; Tsivelikas, A.; Charles, C.; Amri, A. Predictive characterization for seed morphometric traits for genebank accessions using genomic selection. Front. Ecol. Evol. 2020, 8, 32. [CrossRef]

110. Golan, G.; Oksenberg, A.; Peleg, Z. Genetic evidence for differential selection of grain and embryo weight during wheat evolution under domestication. J. Exp. Bot. 2015, 66, 5703-5711. [CrossRef]

111. Liu, Y.; Tao, Y.; Wang, Z.; Guo, Q.; Wu, F.; Yang, X.; Deng, M.; Ma, J.; Chen, G.; Wei, Y.; et al. Identification of QTL for flag leaf length in common wheat and their pleiotropic effects. Mol. Breed. 2017, 38, 11. [CrossRef]

112. Yang, J.; Zhou, Y.; Wu, Q.; Chen, Y.; Zhang, P.; Zhang, Y.E.; Hu, W.; Wang, X.; Zhao, H.; Dong, L.; et al. Molecular characterization of a novel TaGL3-5A allele and its association with grain length in wheat (Triticum aestivum L.). Theor. Appl. Genet. 2019, 132, 1799-1814. [CrossRef]

113. Desiderio, F.; Zarei, L.; Licciardello, S.; Cheghamirza, K.; Farshadfar, E.; Virzi, N.; Sciacca, F.; Bagnaresi, P.; Battaglia, R.; Guerra, D.; et al. Genomic regions from an Iranian landrace increase kernel size in durum wheat. Front. Plant Sci. 2019, 10, 448. [CrossRef]

114. Ma, J.; Zhang, H.; Li, S.; Zou, Y.; Li, T.; Liu, J.; Ding, P.; Mu, Y.; Tang, H.; Deng, M.; et al. Identification of quantitative trait loci for kernel traits in a wheat cultivar Chuannong16. BMC Genet. 2019, 20, 77. [CrossRef]

115. Liu, H.; Ma, J.; Tu, Y.; Zhu, J.; Ding, P.; Liu, J.; Li, T.; Zou, Y.; Habib, A.; Mu, Y.; et al. Several stably expressed QTL for spike density of common wheat (Triticum aestivum) in multiple environments. Plant Breed. 2020, 139, 284-294. [CrossRef]

116. Ma, J.; Tu, Y.; Zhu, J.; Luo, W.; Liu, H.; Li, C.; Li, S.; Liu, J.; Ding, P.; Habib, A.; et al. Flag leaf size and posture of bread wheat: Genetic dissection, QTL validation and their relationships with yield-related traits. Theor. Appl. Genet. 2020, 133, 297-315. [CrossRef] [PubMed]

117. Juliana, P.; Poland, J.; Huerta-Espino, J.; Shrestha, S.; Crossa, J.; Crespo-Herrera, L.; Toledo, F.H.; Govindan, V.; Mondal, S.; Kumar, U.; et al. Improving grain yield, stress resilience and quality of bread wheat using large-scale genomics. Nat. Genet. 2019, 51, 1530-1539. [CrossRef] [PubMed]

118. Liu, J.; Wu, B.; Singh, R.P.; Velu, G. QTL mapping for micronutrients concentration and yield component traits in a hexaploid wheat mapping population. J. Cereal Sci. 2019, 88, 57-64. [CrossRef]

119. Hao, Y.; Velu, G.; Peña, R.J.; Singh, S.; Singh, R.P. Genetic loci associated with high grain zinc concentration and pleiotropic effect on kernel weight in wheat (Triticum aestivum L.). Mol. Breed. 2014, 34, 1893-1902. [CrossRef]

120. Magallanes-López, A.M.; Ammar, K.; Morales-Dorantes, A.; González-Santoyo, H.; Crossa, J.; Guzmán, C. Grain quality traits of commercial durum wheat varieties and their relationships with drought stress and glutenins composition. J. Cereal Sci. 2017, 75, 1-9. [CrossRef]

121. Guzmán, C.; Autrique, J.E.; Mondal, S.; Singh, R.P.; Govindan, V.; Morales-Dorantes, A.; Posadas-Romano, G.; Crossa, J.; Ammar, K.; Peña, R.J. Response to drought and heat stress on wheat quality, with special emphasis on bread-making quality, in durum wheat. Field Crops Res. 2016, 186, 157-165. [CrossRef]

122. Guzmán, C.; Mondal, S.; Govindan, V.; Autrique, J.E.; Posadas-Romano, G.; Cervantes, F.; Crossa, J.; Vargas, M.; Singh, R.P.; Peña, R.J. Use of rapid tests to predict quality traits of CIMMYT bread wheat genotypes grown under different environments. LWT 2016, 69, 327-333. [CrossRef]

123. Magallanes-López, A.M.; Hernandez-Espinosa, N.; Velu, G.; Posadas-Romano, G.; Ordoñez-Villegas, V.M.G.; Crossa, J.; Ammar, K.; Guzmán, C. Variability in iron, zinc and phytic acid content in a worldwide collection of commercial durum wheat cultivars and the effect of reduced irrigation on these traits. Food Chem. 2017, 237, 499-505. [CrossRef]

124. Velu, G.; Ortiz-Monasterio, I.; Cakmak, I.; Hao, Y.; Singh, R.P. Biofortification strategies to increase grain zinc and iron concentrations in wheat. J Cereal Sci. 2014, 59, 365-372. [CrossRef] 
125. Velu, G.; Crossa, J.; Singh, R.P.; Hao, Y.; Dreisigacker, S.; Perez-Rodriguez, P.; Joshi, A.K.; Chatrath, R.; Gupta, V.; Balasubramaniam, A.; et al. Genomic prediction for grain zinc and iron concentrations in spring wheat. Theor. Appl. Genet. 2016, 129, 1595-1605. [CrossRef]

126. Fleitas, M.C.; Mondal, S.; Gerard, G.S.; Hernández-Espinosa, N.; Singh, R.P.; Crossa, J.; Guzmán, C. Identification of CIMMYT spring bread wheat germplasm maintaining superior grain yield and quality under heat-stress. J. Cereal Sci. 2020, 93, 102981. [CrossRef]

127. Hernández-Espinosa, N.; Payne, T.; Huerta-Espino, J.; Cervantes, F.; Gonzalez-Santoyo, H.; Ammar, K.; Guzmán, C. Preliminary characterization for grain quality traits and high and low molecular weight glutenins subunits composition of durum wheat landraces from Iran and Mexico. J. Cereal Sci. 2019, 88, 47-56. [CrossRef]

128. Gehan, M.A.; Fahlgren, N.; Abbasi, A.; Berry, J.C.; Callen, S.T.; Chavez, L.; Doust, A.N.; Feldman, M.J.; Gilbert, K.B.; Hodge, J.G.; et al. PlantCV v2: Image analysis software for high-throughput plant phenotyping. Peer J. 2017, 5, e4088. [CrossRef] [PubMed]

129. Komyshev, E.; Genaev, M.; Afonnikov, D. Evaluation of the SeedCounter, a mobile application for grain phenotyping. Front. Plant Sci. 2017, 7, 1990. [CrossRef]

130. Appels, R.; Eversole, K.; Stein, N.; Feuillet, C.; Keller, B.; Rogers, J.; Pozniak, C.J.; Choulet, F.; Distelfeld, A.; Poland, J.; et al. Shifting the limits in wheat research and breeding using a fully annotated reference genome. Science 2018, 361, eaar7191. [PubMed]

(C) 2020 by the authors. Licensee MDPI, Basel, Switzerland. This article is an open access article distributed under the terms and conditions of the Creative Commons Attribution (CC BY) license (http://creativecommons.org/licenses/by/4.0/). 